\title{
Diabetes Mellitus: A Multifactor Approach
}

\author{
Fabiana Gonçalves Ferreira and Amanda Caroline Cardoso Corrêa Carlos Menezes* \\ Municipal Public Server Hospital, Brazil
}

Received: 眥 March 30, 2018; Published: 制 April 05, 2018

*Corresponding author: Amanda Caroline Cardoso Corrêa Carlos Menezes, Clinical Nutrition Coordinator of Municipal Public Server Hospital, Sao Paulo, Brazil

\section{Introduction}

Diabetes Mellitus (DM) is a chronic non-communicable disease characterized by chronic hyperglycemia due to an impaired glucose metabolism [1-3]. It can occur by an autoimmune process in which there is destruction of the beta cells of the pancreas, leading to deficiency of insulin secretion characterizing the DM type I, which affects children and adolescents, may be due to a combination of insulin resistance and the inadequate compensatory response to insulin secretion, predominant in the DM type II, affecting adults when glucose intolerance occurs during the second or third trimester of gestation, it is characterized gestational DM (GDM), and other types of diabetes are reported in the literature, such as those caused by genetic defects of beta cell function, disorders genetics in the action of insulin, exocrine pancreatic diseases, endocrinopathies, drug induced or other age chemical infections, viral infections, unusual immunological forms, and genetic syndromes associated with diabetes $[4,5]$.

In 2013, according to the IDF (International Diabetes Federation), 328 million people with diabetes have been registered worldwide. It is expected a significant increase of $60 \%$ in Central and South America, leading to an incidence of 592 million by the end of 2035 [5]. DM is the sixth leading cause of death in adults in the United States. This chronic disease affects $8.3 \%$ of the population, or about 25.8 million people in the US. Among adults over 65 years old, 10.9 million are affected, which represents $26.9 \%$ of this age group. The prevalence of DM is higher in people over 65 years of age, however, have already shown a larger increase in the last decade in younger adults and is increasing due to among other reasons, to changes in diet, aging, urbanization, by the increase of the prevalence of obesity and physical inactivity [6]. DM is accompanied by several complications such as ischemic heart disease, heart failure, stroke and arterial hypertension. Hypertension is twice as frequent in the diabetic patient as in the general population. DM it is the main cause of amputation of lower limbs and blindness, about $26 \%$ of patients who enter dialysis programs are diabetic [710]. Several studies have shown that strict glycemic control is able to reduce the complications of diabetes [11-13].
The approach to diabetes consists of medication and non-drug intervention, always accompanied by changes in lifestyle, thus, the success of the control of glycemia rates depends on patient adherence to treatment and health practices that stimulate or facilitate lifestyle change $[7,14,15]$. According to the American Diabetes Association, the best nutritional strategy for health promotion and chronic disease risk reduction is to obtain adequate nutrients from a varied, moderate and balanced diet based on the pillars of the Food Pyramid [16]. The recommended diet for diabetic patients should be high in fibre, with low levels of saturated fat, salt and simple sugars. Soluble fibre favours the control of dyslipidemia and glycemia, by reducing the absorption of cholesterol and carbohydrates in the intestinal environment. Low-carbohydrate, low-protein and low-lipids diets are especially indicated for diabetic patients [17]. Within the dietary approach, several trends have become essential tools for disease therapy, a new option that stands out are functional foods [18].

Several studies have stated that the inclusion of legumes in the diet plays an important role in the prevention of diseases such as diabetes, cancer and coronary heart disease $[19,20]$. In addition to the benefit due to the role of fibres, recently the action of the present polyphenols and their effects related to glucose metabolism should be highlighted. Dietary polyphones, presents in cocoa, tea, coffee, grape, red wine and others may inhibit $\alpha$-amylase and $\alpha$-glycosidase, inhibit glucose absorption in the intestine by sodium-dependent glucose transporter 1 (SGLT1), stimulate insulin secretion and reduce hepatic glucose output [21,22]. Several studies with foods shown evidence of a reduction in glucose absorption and glycemic control related to these polyphenols. Works with different leaf amaranths have shown positive effects in terms of reducing hyperglycemias, Amaranthus caudatus can inhibit the $\alpha$-amylase under in in vitro conditions. The extracts contained flavonoids, saponins, alkaloids, carbohydrates, proteins, amino acids and other phenolic compounds [23]. DM type II has modifiable risk factors, therefore, feeding should be used as a preventive measure as a supporting in the treatment of the disease. 
Food plays an extremely important role in glycemic control and, in addition, is able to prevent diabetes complications.

\section{References}

1. Oliveira KCS, Zanetti ML (2011) Conhecimento e atitude de usuários com diabetes mellitus em um Serviço de Atenção Básica à Saúde. Rev Esc Enferm USP 45 (4): 862-868.

2. (2006) Diabetes Mellitus/Ministry of Health, Ministry of Health, Secretariat of Health Care (BR), Department of Basic Attention, Department of Health Care, Department of Primary Care, (DF): Ministry of Health, Brazil, p. 56.

3. Duncan BB, Schmidt MI, Giugliani ERJ (2004) Diabetes Melito: diagnosis, classification and initial approach. Outpatient medicine: primary care based on evidence, ( $3^{\text {rd }}$ edn). Porto Alegre (RS): Artmed pp. 669-676.

4. (2010) Diagnosis and classification of diabetes mellitus, American Diabetes Association, Diabetes Care 33(Suppl 1): S62-69.

5. (1996) American Diabetes Association. Clinical practice recommendations, Diabetes Care 19(Suppl 1): S1-118.

6. (2018) IDF Diabetes Atlas $8^{\text {th }}$ (edn). Belgium.

7. (2013) FEDERATION, Internation Diabetes. IDF diabetes atlas. Brussels: International Diabetes Federation, Belgium.

8. Silvestre JA (1997) SUS hospitalizations. Coordination of Health Care of the Elderly, Ministry of Health, Brasília.

9. (1993) HDS Hypertension in Diabetes Study Group HDS: I Prevalence of hypertension in newly presenting type 2 diabetic patients and association with risk factors for cardiovascular and diabetic complications. Journal of Hypertension, London 11(3) 309-317.

10. Spichler ERS (1998) Diabetic lower extremities amputation. Diabetologia, Rio de Janeiro 41(A279): 90-96.

11. Schellini SA (1994) Diabetes, diabetic retinopathy and blindness. Jornal Brasileiro de Medicina Rio de Janeiro 67(2): 171-174.

12. Bruno R, Gross JL (2000) Prognostic factors in Brazilian diabetic patients starting dialysis: a 3,6 year follow-up study. J Diabetes Complications, Nova Iorque 14(5): 266-271.
13. (1998) UKPDS 34-UK Prospective Diabetes Study Group. Intensive blood-glucose control with sulfonylureas or insulin compared with conventional treatment and risk of complications in patients with type 2 diabetes: UKPDS 34. Lancet, London 352(9131): 854-865.

14. (1998) Tight blood pressure control and risk of macrovascular and microvascular complications in type 2 diabetes: UKPDS 38. UKPDS 38UK Prospective Diabetes Study Group, BMJ; London 317(7160): 703712 .

15. Mion JRD (2018) Arterial Hypertension: general approach. Project Guidelines AMB / CFM 2002a.

16. Terezinha Rodrigues Silva, Chaie Feldmam, Maria Helena A Lima, Moacyr R Cuce Nobre, Rachel Z L Domingues (2006) Control of Diabetes Mellitus and Arterial Hypertension with Educational and Therapeutic Intervention Groups in Outpatient Follow - up of a Basic Health Unit Rev Saúde e Sociedade 15(3): 180-189.

17. (2005) American Diabetes Association, Standards of medical care in diabetes. Diabetes Care 28(Suppl1): S4-S36.

18. (2004) American Diabetes Association, Nutritional principals and recommendations in diabetes. Diabetes Care 27(Suppl 1): S36-S46.

19. Corrêa PCC (2017) Perception of carriers attended in the family health strategy on type 2 diabetes mellitus. Revista de enfermagem UFPE 11.

20. Campos vega R, loarca piña G, Oomah BD (2010) Minor components of pulses and their potential impact on human health. Food research international 43(2): 461-482.

21. Heiner Boeing, Angela Bechthold, Achim Bub, Sabine Ellinger, Dirk Haller, et al. (2012) Critical review: vegetables and fruit in the prevention of chronic diseases. European journal of nutrition 51(6): 637-663.

22. Kim Y, Keogh JB, Clifton PM (2016) Polyphenols and glycemic control. Nutrients 8(1): 17.

23. Arêas JAG, Carlos menezes ACCC, Soares RAM, Amaranth (2016) Encyclopedia of Food and Health. 1a ed Elsevier pp.135-140.
This work is licensed under Creative Commons Attribution 4.0 License

To Submit Your Article Click Here : Submit Article

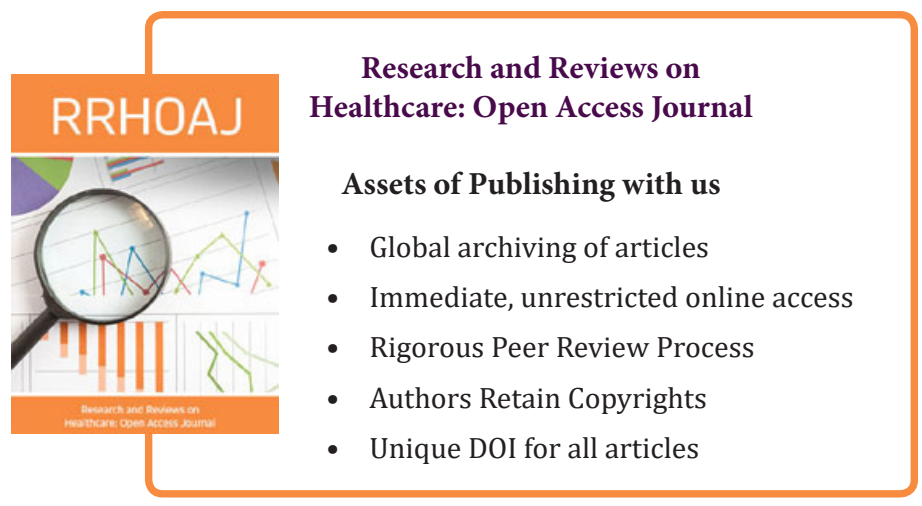

